\title{
Perceived sensitivity of mammographic screening: women's views on test accuracy and financial compensation for missed cancers
}

\author{
Alexandra Barratt, Jill Cockburn, Colin Furnival, Amanda McBride, Louise Mallon
}

\begin{abstract}
Objectives-To estimate women's expectations of the accuracy of screening mammography and to explore attitudes towards compensation for missed cancers.

Design-Cross sectional survey (by telephone).

Setting-Australia; population-based survey conducted in April 1996.

Participants-Random sample of women aged 30-69 years. A total of 2935 women completed the Breast Health Survey (adjusted response rate $65 \%$ ). A random sample of 115 completed this sub-survey on perceived sensitivity of mammographic screening and compensation for missed cancers.
\end{abstract}

Results-About one third of women $(32.2 \%, 95 \%$ CI $23.7,40.7)$ had an unrealistically high expectation of the sensitivity of screening mammography, reporting it to be $\mathbf{9 5 \%}$ or higher. Approximately $\mathbf{4 0 \%}$ of the women $(43.5 \%, 95 \% \mathrm{CI} 34.4,52.6)$ thought that screening mammography should pick up all cancers (should have a sensitivity of $100 \%$ ). Just under half the women $(45.2 \%, 95 \%$ CI $36.1,54.3)$ said financial compensation should be awarded for a cancer missed by screening mammography even if the cancer was missed as a consequence of the small failure rate of the test. Younger women living in metropolitan areas and women who had realistic expectations of the accuracy of the tests were more likely to favour financial compensation.

Conclusion-Unrealistically high expectations of the sensitivity of screening mammography were common in this group of women. Many women favoured financial compensation for missed cancers even if the cancer was missed solely because of the failure rate of the test. Public education is required to inform women of the limited sensitivity of breast cancer tests but this may not reduce claims for financial compensation when cancers are missed.

( Epidemiol Community Health 1999;53:716-720)

Correspondence to:

Dr A Barratt, Department of Public Health and

Community Medicine,

Building A27, University of

Sydney, NSW, 2006

Australia.

Accepted for publication 23 March 1999 the range $75 \%$ to $95 \% .{ }^{12}$ There is evidence that women are not well informed about the accuracy of screening mammography and may not be aware of the false negative rate (1- sensitivity). A recent survey of 58 pamphlets about mammographic screening in Australia found that information about the accuracy of screening mammography was provided only occasionally, with a quarter of pamphlets giving information about sensitivity and none giving information about specificity. ${ }^{3}$ Earlier work showed that $35 \%$ of women thought that screening mammography would detect breast cancer in $95-100 \%$ of cases. ${ }^{4}$ Some authors have speculated that this ignorance contributes to a sense of anger and betrayal if a cancer is missed, which may make women more likely to sue for negligence and financial compensation. ${ }^{5}$

Women have already successfully sued for false negative results in the context of diagnostic tests (that is, tests applied to symptomatic women) in Australia. For example, in 1994 an Australian woman successfully sued a pathology laboratory for the delay in diagnosing her cancer of the cervix after a negative Pap smear, taken to investigate irregular vaginal bleeding. ${ }^{6}$ To the best of our knowledge no one has successfully sued for negligence over a false negative result of a screening test in Australia although it is impossible to determine what cases may have been settled out of court. Therefore it remains unclear whether a similar outcome may be achieved in the screening context. It has been argued that successful claims against a screening programme could render the breast and cervical screening programmes in Australia unsustainable because of increasing costs and increasing overdetection and overtreatment of minor abnormalities. ${ }^{78}$ Similar concerns have been expressed in the $\mathrm{UK}^{9}{ }^{10}$ and the USA. ${ }^{11}$ It has been suggested that public education emphasising that screening tests are not, even at the highest levels of practice, $100 \%$ accurate may be helpful. ${ }^{58911}$

\section{Methods}

We used the 1996 National Breast Health Survey (undertaken by the National Health and Medical Research Council's National Breast Cancer Centre) to undertake some exploratory work on women's expectations about the accuracy of screening mammography and their attitudes towards legal action and financial compensation for missed cancers. A detailed description of the survey has been published. ${ }^{12}$ 
Table 1 Sociodemographic profile of participants compared with whole survey group and Australian national data

\begin{tabular}{|c|c|c|c|c|}
\hline \multirow[b]{2}{*}{ Characteristic } & \multirow{2}{*}{$\begin{array}{l}\text { ABS (Australian } \\
\text { national data) } \\
\%\end{array}$} & \multirow{2}{*}{$\begin{array}{l}\text { Breast Health } \\
\text { Survey } \\
(n=2935) \%\end{array}$} & \multicolumn{2}{|c|}{$\begin{array}{l}\text { Subset reported here } \\
(n=115)\end{array}$} \\
\hline & & & $\%$ & Number \\
\hline \multicolumn{5}{|l|}{ Age $(y)$} \\
\hline $30-39$ & 33.2 & 30.7 & 31.3 & 36 \\
\hline $40-49$ & 30.1 & 31.7 & 32.2 & 37 \\
\hline $50-59$ & 20.6 & 22.1 & 23.5 & 27 \\
\hline $60-69$ & 16.1 & 15.3 & 13.0 & 15 \\
\hline \multicolumn{5}{|l|}{ Marital status } \\
\hline Never married & 5.8 & 5.8 & 6.1 & 7 \\
\hline Married/de facto & 78.5 & 79.7 & 72.2 & 83 \\
\hline $\begin{array}{l}\text { Separated/divorced/widowed } \\
\text { Post-school education }\end{array}$ & 15.8 & 14.5 & 21.7 & 25 \\
\hline None & 54.0 & 47.1 & 40.9 & 47 \\
\hline Trade certificate & 3.1 & 4.2 & 6.1 & 7 \\
\hline Degree or higher & 14.6 & 17.7 & 11.3 & 13 \\
\hline Other & 28.3 & 31.0 & 41.7 & 48 \\
\hline \multicolumn{5}{|l|}{ Household income } \\
\hline$\$ 0-19999$ & N/A & & 20.0 & 23 \\
\hline$\$ 20000-29999$ & & & 17.4 & 20 \\
\hline$\$ 30000$ and over & & & 38.4 & 44 \\
\hline Can't say/refused & & & 24.3 & 28 \\
\hline \multicolumn{5}{|l|}{ Country of birth } \\
\hline Australia & 69.2 & 76.0 & 71.3 & 82 \\
\hline Other & 30.8 & 24.0 & 28.7 & 33 \\
\hline \multicolumn{5}{|l|}{ Language spoken at home } \\
\hline English & N/A & 96.6 & 98.3 & 113 \\
\hline Chinese language & & 0.3 & 0.9 & 1 \\
\hline European language & & 2.1 & 0.9 & 1 \\
\hline Other & & 1.0 & 0 & \\
\hline \multicolumn{5}{|l|}{ Employment } \\
\hline Full time & 26.2 & 27.9 & 28.7 & 33 \\
\hline Part-time & 27.9 & 29.1 & 28.7 & 33 \\
\hline Looking for work & 3.3 & 3.9 & 4.3 & 5 \\
\hline Not looking for work & 42.6 & 39.1 & 38.3 & 44 \\
\hline Have ever had a mammogram & 50.0 & 55.0 & 57.4 & 66 \\
\hline
\end{tabular}

Briefly, the Breast Health Survey was conducted nationally by telephone by a market research company on behalf of the National Breast Cancer Centre (NBCC) in April 1996 to estimate current knowledge and behaviour in relation to breast cancer and early detection practices. A simple random sample of 3000 women aged 30-69 years was used with stratification by State and by area of residence (urban and rural).

A random sample $(n=115)$ of all respondents to the Breast Health Survey were asked an extra set of questions about medicolegal aspects of diagnosis, the results of which are reported in this paper. The medicolegal questions were developed specifically for this work; they were based on previous work by Cockburn et $a l^{4}$ and were qualitatively pilot tested with 20 volunteers, revised and pilot tested again with a further 100 volunteers before the main survey. Only 115 women were asked these additional questions as we estimated that $95 \%$ confidence limits of approximately $+/-10 \%$ would be adequately precise and because it was not considered feasible to ask all women to spend the extra 20 minutes that was required to answer these questions.

VALIDATION OF THE SURVEY

To assess potential selection bias we obtained data from February 1996 Australian Bureau of Statistics (ABS) Population Survey Monitor, which is conducted quarterly by household interview for the Commonwealth Government to supplement census data. In addition we placed one of our questions, "Have you ever had a mammogram?", into the ABS survey. The question was asked only of women 30-69 years in the ABS survey to provide a result comparable with our study.

\section{STATISTICAL METHODS}

SPSS statistical package was used for all analyses. We calculated $95 \%$ confidence intervals for important proportions. Where it was necessary to compare means, a $t$ test for independent samples was used and differences in proportions were compared using the $\chi^{2}$ statistic. Logistic regression using backwards stepwise elimination of variables was used to model the predictors of favouring financial compensation. We calculated 95\% confidence intervals around the coefficient estimates and exponentiated to give the confidence intervals around the estimated odds ratios.

\section{Results}

RESPONDENT CHARACTERISTICS AND RESPONSE RATE

The raw response rate (completed interviews over contacted eligible women) was $70.2 \%$; the adjusted response rate (adjusting for eligible women among those who could not be contacted) was $64.4 \%$. The results reported here are based on responses from 115 women who were chosen at random from the total sample of 2935 women to complete extra questions on medicolegal issues. These women were similar to the total group in sociodemographic characteristics (table 1); for example the mean age of the subset of 115 women was 46.38 years compared with 46.35 years for the whole group $(t=0.036, \mathrm{p}=0.972)$ and there were no differences in the proportions of women living in urban and rural/ remote areas $\left(\chi^{2}=1.077, p=0.30\right)$. The women in both the total survey group and the subset reported here were similar to Australian national data as measured by the Australian Bureau of Statistics (table 1). ${ }^{13}$ Approximately half the women $(57.4 \%)$ had ever had a mammogram, which is close to the national average of $50 \%$ (table 1 ).

\section{PERCEIVED SENSITIVITY OF SCREENING}

\section{MAMMOGRAPHY}

Women were asked: "Imagine a situation where 100 women really have early breast cancer but the cancer is as yet undetected. Along with many other women they all have a screening mammogram (to detect breast cancer before any symptoms, like a lump, are present). On average, how many of the 100 women do you think the mammogram would pick up?" The meaning of each woman's response was checked by asking "So that means that it would pick up ...\% of the cancers and miss ...\% is that right?" in an iterative fashion until the respondent and the interviewer agreed upon the percentage picked up.

In subsequent questions, women were asked ".... realistically how many of these 100 women do you think the test should pick up?" and "Of the 100 women who actually have breast cancer, what would you say would be the absolute minimum number that the screening mammogram should detect to be called a worthwhile test?" 
Table 2 Women's estimates of the sensitivity of screening mammography (correct answer for current sensitivity shown in italics)

\begin{tabular}{|c|c|c|c|c|c|c|}
\hline \multirow[b]{3}{*}{ Sensitivity (\%) } & \multicolumn{6}{|c|}{ Women reporting each category of sensitivity for: } \\
\hline & \multicolumn{2}{|c|}{$\begin{array}{l}\text { Cancers that are } \\
\text { currently detected } \\
\text { by screening }\end{array}$} & \multicolumn{2}{|c|}{$\begin{array}{l}\text { Cancers that should } \\
\text { be detected by } \\
\text { screening }\end{array}$} & \multicolumn{2}{|c|}{$\begin{array}{l}\text { The minimum number of cancers } \\
\text { that should be detected for } \\
\text { screening to be worthwhile }\end{array}$} \\
\hline & $\%$ & $(\mathrm{n})$ & $\%$ & (n) & $\%$ & (n) \\
\hline $0-59$ & 13.9 & $(16)$ & 9.6 & (11) & 20.9 & $(24)$ \\
\hline $60-79$ & 13.0 & (15) & 4.3 & (5) & 7.0 & $(8)$ \\
\hline $80-89$ & 14.8 & (17) & 5.2 & (6) & 9.6 & (11) \\
\hline $90-94$ & 20.0 & (23) & 14.8 & (17) & 16.5 & (19) \\
\hline $95-99$ & 28.7 & (33) & 19.1 & $(22)$ & 21.7 & $(25)$ \\
\hline 100 & 3.5 & (4) & 43.5 & (50) & 13.9 & (16) \\
\hline Can't say & 6.1 & $(7)$ & 3.5 & $(4)$ & 10.4 & $(12)$ \\
\hline Total & 100 & 115 & 100 & 115 & 100 & $(115)$ \\
\hline
\end{tabular}

Table 2 gives the responses to these questions.

There was substantial variation in women's estimates of the sensitivity of screening mammography; only $35 \%(34.8 \%, 95 \%$ CI 26.1 , 43.5) reported it to be in the range of $80-94 \%$, which is correct allowing for the known variation in sensitivity by age. However, about one third $(32.2 \%, 95 \%$ CI $23.7,40.7)$ had unrealistically high expectations of the sensitivity, reporting it to be over $95 \%$.

Almost half the women $(43.5 \%, 95 \% \mathrm{CI}$ $34.4,52.7)$ thought that screening mammography "realistically should" pick up all cancers (that is, should be $100 \%$ ), and three quarters of the women $(77.4 \%, 95 \%$ CI $69.8,85.0)$ reported that the sensitivity should be over $90 \%$.

Nevertheless, women were prepared to accept much lower sensitivities before deciding that screening would not be worthwhile. Only $14 \%$ of women $(13.9,95 \%$ CI $7.6,20.2)$ said $100 \%$ of cancers should be detected for screening to be worthwhile. About half the women $(52.1 \%, 43.0,61.2)$ reported screening would be worthwhile if sensitivity was $90 \%$ or better.

PROPORTION OF WOMEN FAVOURING

COMPENSATION FOR A BREAST CANCER MISSED BY SCREENING

Women were asked "A woman who has undetected early breast cancer is invited to have a screening mammogram. Due to the small error rate of the test the cancer is not picked up at this stage. The cancer is detected only at a later stage by a separate test. Do you think this woman should receive compensation?" Subsequently women were asked a similar question but in a situation where the cancer was not detected because someone involved in performing the test made a negligent error, for instance did not pass on an abnormal result.

Table 3 Predictors of being in favour of financial compensation for false negative screening result

\begin{tabular}{lrlll}
\hline & \multicolumn{1}{c}{ OR } & $\begin{array}{l}\text { OR } \\
(\operatorname{Exp} B)\end{array}$ & $(95 \% \mathrm{CI})$ & $\begin{array}{l}\text { Significance } \\
(p)\end{array}$ \\
\hline Constant & 0.673 & & & \\
Age & -0.052 & 0.950 & $0.91,0.99$ & 0.026 \\
Area of residence (metropolitan) & 1.816 & 6.147 & $1.72,21.93$ & 0.005 \\
$\begin{array}{l}\text { Risk perception (low to average) } \\
\text { Expectation of accuracy of screening }\end{array}$ & 1.071 & 2.919 & $1.12,7.58$ & 0.028 \\
$\quad$ mammography (unrealistically high) & -0.994 & 0.370 & $0.14,0.97$ & 0.042 \\
\hline
\end{tabular}

Forty five per cent of women $(45.2 \%$, $95 \% \mathrm{CI} 36.10,54.3)$ were in favour of financial compensation being awarded if the breast cancer was missed because of the failure rate of the screening test. However, if the cancer was missed because of a negligent error made by someone in the screening process, 93\% $(95 \%$ CI $88.3,97.7)$ of women thought compensation should be awarded.

PREDICTORS OF FAVOURING COMPENSATION FOR A BREAST CANCER MISSED BY SCREENING (BECAUSE OF THE FAILURE RATE OF THE TEST) In the main survey women were asked questions about breast cancer incidence and about their perceived likelihood of getting breast cancer. ${ }^{13}$ From the responses to these questions variables were constructed to represent women's knowledge about breast cancer (based on whether she could accurately report the breast cancer incidence in Australia) and her perceived risk as either low to average $(<12 \%)$ or high $(>12 \%)$. In addition a variable based on whether women were realistic or unrealistic in their beliefs about the sensitivity of screening mammography was constructed from the data presented in table 2 . Women who thought that the sensitivity of screening mammography is $95 \%$ or greater were classified as unrealistic.

The major sociodemographic factors (age, education, and area of residence) plus the developed variables outlined above, were tested in the logistic regression model because it was thought a priori that these variables might influence women's views and univariate analysis supported this. A personal history of mammography was not associated with favouring compensation in univariate analysis (women were just as likely to favour compensation whether they had had a mammogram or not, $\left(\chi^{2}=0.21, p=0.88\right)$ so this variable was not entered into the model.

Significant predictors of favouring financial compensation even if the delay was attributable to the error rate of the test were younger age, residence in an urban rather than a rural area, a realistic perception of the accuracy of screening mammography and a perception that one's own risk of breast cancer is about population average or less (table 3).

MOTIVATION FOR LEGAL ACTION

Women were asked "If a woman did take legal action to obtain compensation because her breast cancer was not diagnosed for whatever reason, what do you think her main motivation would be for taking legal action?"

Their responses are given in table 4. Many of the responses were centred around issues of financial need both for the woman (for treatment) and for her family.

\section{ALTERNATIVES TO TAKING LEGAL ACTION}

Women were asked "Imagine a woman did take legal action to obtain compensation because her breast cancer was not diagnosed for whatever reason, what alternatives might be useful or acceptable to her instead of taking legal action?” 
Table 4 Suggested reasons for starting legal action

\begin{tabular}{lrr} 
& \multicolumn{2}{c}{ Frequency } \\
\cline { 2 - 3 } Reason & $\%$ & number \\
\hline Provide financial stability/compensation for her family & 22.6 & 26 \\
To prevent it happening to someone else & 12.2 & 14 \\
She could die/lose a breast from it & 11.3 & 13 \\
Anger/bitterness & 7.8 & 9 \\
Make the people doing the test more responsible & 6.1 & 7 \\
Help pay medical bills/afford treatment & 5.2 & 6 \\
Publicity to expose negligence of person responsible & 4.3 & 5 \\
Psychological satisfaction & 1.7 & 2 \\
Revenge/vindictiveness & 0.9 & 1 \\
Other & 10.4 & 12 \\
Can't say & 17.4 & 20 \\
Total & 100 & 115 \\
\hline
\end{tabular}

Most women said there was no alternative to taking legal action $(6 \%)$ or were unable to answer this question (63\%). However, a few alternatives were offered that primarily related to some form of financial assistance or out of court payment to cover medical costs and family expenses $(10 \%)$ or the provision of counselling services $(5 \%)$.

\section{Discussion}

Although our sample was small, there is little evidence of selection bias as there were no important sociodemographic differences between the subset of women whose results are presented here, our total survey population $(n=2935)$ and the Australian population as measured by the Australian Bureau of Statistics $^{13}$ (table 1).

Women have been shown to overestimate both their chances of getting breast cancer and the effectiveness of screening in reducing breast cancer mortality. ${ }^{14}$ This study provides evidence that women also overestimate the accuracy of mammographic screening and is consistent with the earlier study by Cockburn et al. ${ }^{4}$ Furthermore, we found that almost half the women thought that screening mammography "realistically should" pick up all cancers (that is, should be $100 \%$ ). The previous study was done in 1994, which suggests that public knowledge about screening mammography has not improved and expectations of accuracy are still high. This is not surprising given the enthusiastic way in which mammographic screening has been promoted, often with limited acknowledgement of the potential for both false negative and false positive results. ${ }^{3}{ }^{15}$ Unfortunately we did not collect any information on the perceived specificity of mammographic screening. This should be investigated because it seems likely that many women may also be unaware of the likelihood of a false positive result and its potential consequences.

This study suggests that most women in Australia think that compensation should be awarded in cases where there is negligence on the part of one or more health professionals leading to a delayed diagnosis. Fewer, but still about half of surveyed women, thought financial compensation should be awarded for missed cancers even if the cancer was missed because of the error rate of the test and not because of negligence. Many women nominated financial needs as the primary motivation for seeking compensation, which suggests that a system of no fault compensation for false negative reports, similar to systems of compensation for adverse effects after immunisation, might be helpful.

False negative results may occur for several reasons. Firstly, the cancer may have arisen after the mammogram, that is it may be an interval cancer that presents clinically before the next screen is due. Alternatively the cancer may have been present at the time of the mammogram but was missed either through negligent or non-negligent error. Resolving these distinctions may prove difficult in the courts as the issues are even more complex than they are around errors in diagnostic tests. In the case referred to earlier ${ }^{6}$ the judge determined that the interpretation of the smear made by the pathology company could not be explained as an acceptable different interpretation. Therefore the only explanation was that the interpretation was wrong and the error was made negligently. The decision as to whether a false negative report from a screening test is negligent rests with the judge hearing the case and presumably the decision will be made along the same lines. Currently therefore the outcome of such a case is unpredictable. This uncertainty has led to calls for statutory immunity from suit for providers of screening services who comply with certain standards of care as laid down by an appropriate accrediting agency. ${ }^{16}$

Information about both the false negative and false positive rate of screening tests should be provided so that people are better able to make an informed choice about participation in screening. In addition, it needs to be clear that a negative result does not completely exclude disease and tells nothing about whether disease will develop in the future.

Although it is intuitively appealing to think that if women have realistic information about the accuracy of mammographic screening they will be less inclined to seek financial compensation for missed cancers, this may not be the case. The results of this study suggest that as women's knowledge about the true accuracy of screening mammography increases we might expect that more women may seek financial compensation for missed cancers.

In conclusion, many women have unrealistically high expectations of the sensitivity of screening for breast cancer. About half of women favoured financial compensation for missed cancers even if the cancer was missed solely because of the failure rate of the test. Predictors of favouring compensation included young age and realistic expectations of the accuracy of tests. Consideration needs to be given to the legal status of non-negligent false results and alternative ways of compensating women whose cancers are missed. Public education is required to inform women of the accuracy of mammographic screening but this may not modify the widely held view that compensation should be sought when cancers are missed. 
Funding: this study was funded entirely by the National Health and Medical Research Council National Breast Cancer Centre. Conflicts of interest: none.

1 Mushlin AI, Kouides RW, Shapiro DE. Estimating the accuracy of screening mammography: a meta-analysis. $\mathrm{Am}$ 7 Prev Med 1998;14:143-53.

2 Kerlikowske K, Grady D, Barclay J, et al. Effect of age, breast density and family history on the sensitivity of first screening mammography. $\mathscr{F} A M A$ 1996;276:33-8.

3 Slaytor E, Ward JE. How risks of breast cancer and benefits of screening are communicated to women: analysis of 58 pamphlets. BMF 1998;317:263-4.

4 Cockburn J, Redman S, Hill D, et al. Public understanding of medical screening. f Med Screen 1995;2:224-7.

5 Raffle AE. Informed participation in screening is essential. BMF 1997;314:1762.

6 O'Shea-v-Sullivan and Macquarie Pathology Services Pty Ltd [1994]. Aust Torts Reports 81-273.

7 Stanley F. Litigation versus science: what's driving decisionmaking in medicine? Western Australian Law Review making in medicir
8 Mitchell H. Report disclaimers and informed expectations about Papanicolaou smears. An Australian view. Arch about Papanicolaou smears. An
Pathol Lab Med 1997;121:327-30.

9 Slater DN. False-negative cervical smears: medico-legal fallacies and suggested remedies. Cytopathology 1998;9:145-54.

10 Raffle A. New tests in cervical screening. [Letter]. Lancet 1998;351:297.

11 Frable WJ, Austin RM, Greening SE, et al. Medicolegal Affairs IAC Task Force Summary. Acta Cytol 1998;42:76132.

12 Barratt AL, Cockburn J, Redman S, et al. Mammographic creening: Results from the 1996 National Breast Health Survey. Med f A ust 1997;167:521-4.

13 Barratt AL, Cockburn J, Lowe J, et al. Report on the 1996 Breast Health Survey. Sydney: NHMRC National Breast Cancer Centre, 1997.

14 Black WC, Nease RF, Tosteson ANA. Perceptions of breast cancer risk and screening effectiveness in women younger
than 50 years of age. $\mathcal{F}$ Natl Cancer Inst 1995;87:720-31.

15 Roberts MM. Breast screening: time for a rethink? BMF 1989;299:1153-5.

1989;299:1153-5.
Parliament of Victoria Law Reform Committee. The legal Parliament of Victoria Law Reform Committee. The legal Printer, 1997:28-32. 